\title{
Emerging clinical applications of high-intensity focused ultrasound
}

\author{
Nguyen Minh Duc 10 \\ Bilgin Keserci ৫
}

From the Department of Radiology (N.M.D. $ه$ bsnguyenminhduc@pnt.edu.vn),Pham Ngoc Thach University of Medicine, Ho Chi Minh City, Vietnam; Department of Radiology (B.K.), Universiti Sains Malaysia School of Medical Sciences, Kelantan, Malaysia; Department of Radiology (B.K.), Hospital Universiti Sains Malaysia, Kelantan, Malaysia.

*Nguyen Minh Duc and Bilgin Keserci contributed equally to this article.

Received 14 December 2018; revision requested 05 February 2019; last revision received 05 March 2019; accepted 06 March 2019.

Published online 4 July 2019.

DOI 10.5152/dir.2019.18556

\section{ABSTRACT}

High-intensity focused ultrasound (HIFU) is a minimally-invasive and non-ionizing promising technology and has been assessed for its role in the treatment of not only primary tumors but also metastatic lesions under the guidance of ultrasound or magnetic resonance imaging. Its performance is notably effective in neurologic, genitourinary, hepato-pancreato-biliary, musculoskeletal, oncologic, and other miscellaneous applications. In this article, we reviewed the emerging technology of HIFU and its clinical applications.
U Itrasound is an acoustic wave with frequencies greater than the hearing threshold of humans and can be used for both diagnostic and therapeutic purposes in medicine. Diagnostic ultrasound imaging uses ultrasonic pressure waves to image the human interior, whereas therapeutic ultrasound uses alternating compression and rarefaction of sound waves for therapeutic benefit, based on the simple principle of focusing energy waves on a targeted point to produce a thermal effect (Fig. 1). Diagnostic medical ultrasound is typically in the range of 3-20 MHz, while the majority of therapeutic ultrasound typically resides in the $0.54-2 \mathrm{MHz}$ range (1).

High-intensity focused ultrasound (HIFU) is a minimally invasive and non-ionizing technology and currently performs an important clinical role in many fields with abundant evidence on safety and efficacy. Therapeutic application of the HIFU modality, which can be used to treat many diseases by utilizing either thermal energy to induce denaturation of proteins or non-thermal energy to destroy tissue, is considered a rapidly emerging field (1). The HIFU beam passes through soft tissue, elevating the temperature at the target area $\left(>55^{\circ} \mathrm{C}\right)$, thus generating cell death via local coagulative necrosis, which is the main principle for tumor cell damage. HIFU can hence be performed for chosen tissue elimination by generating well-defined volumes of coagulative necrosis deep inside the body without harming the surrounding tissues (Figs. 2, 3) (2).

The biological effects of HIFU were investigated first in 1927 by Wood and Loomis (3). In the 1940s, the first therapeutic trial with focused ultrasound, performed by Lynn et al. (4) to treat tumors in bovine liver, suggested that a geometrically concave transducer could be exploited to elevate the local intensity by focusing the ultrasonic energy without harming the adjacent tissues, while surrounding areas are maintained at low intensity. In the 1950s, the Fry brothers (5) designed and tested the HIFU device for the treatment of neurologic disorders (e.g., Parkinson's disease). However, these early efforts at using HIFU ablation were hampered due to technologic limitations, such as lack of suitable image guidance, and were therefore discontinued in the clinical setting.

Advances in ultrasound imaging and magnetic resonance imaging (MRI) modalities in the 1990s facilitated improved planning of HIFU treatment and monitoring of responses in real-time, and the recent development of high-power ultrasound transducers compatible with these imaging modalities has helped overcome the biggest obstacle in the field of therapeutic ultrasound. 
As technology has improved, recognition and usefulness of HIFU has grown dramatically for many areas of the body, such as the brain, thyroid, liver, kidney, pancreas, breast, uterus, prostate, and bone. Furthermore, in the last two decades, HIFU, which is a novel and alternative therapeutic option to the conventional therapies, has been performed to treat many diseases of different solid organs. Given the rapid development of this method, we reviewed this new emerging technology as image guidance in HIFU and its clinical applications based on the organ systems: neurology, gynecology, urology, hepato-pancreato-biliary, musculoskeletal system, breast and thyroid as shown in the Table.

\section{Emerging technology: image guidance in HIFU}

Emerging technology of HIFU could expand into several treatment areas as a minimally-invasive alternative to conventional surgery. Reliable image guidance is an essential prerequisite of HIFU treatment for patient selection, treatment planning, real-time treatment monitoring, safe delivery of the desired therapeutic dose, and treatment efficacy evaluation.

Most HIFU treatments are still performed under ultrasound imaging guidance mainly due to its cost-effectiveness and greater accessibility to patients (Fig. 4). It is the only modality that can produce data in real time. However, despite these potential benefits, there are several limitations associated with ultrasound imaging: (i) identification of the target volume; (ii) 3D planning; (iii) poor tissue-contrast between targeted lesion and surrounding tissue; (iv) degradation of the image quality during the treatment; $(v)$ lack of quantitative feedback regarding tissue temperature, which limits intraprocedural

\footnotetext{
Main points

- Ultrasound can be utilized as a therapeutic energy.

- Ultrasound and MRI are two guidance modalities integrated with high-intensity focused ultrasound (HIFU).

- HIFU is a minimally-invasive and non-ionizing treatment.

- Emerging HIFU technology is poised to become an alternative or adjunct to current standard treatments.
}

assessment; and (vi) post-treatment lesion assessment (6).

Recent technologic advances in HIFU have resulted in a shift towards MRI guidance, with MRI used extensively for real-time identification and localization of abnormal tissue to be targeted, treatment planning

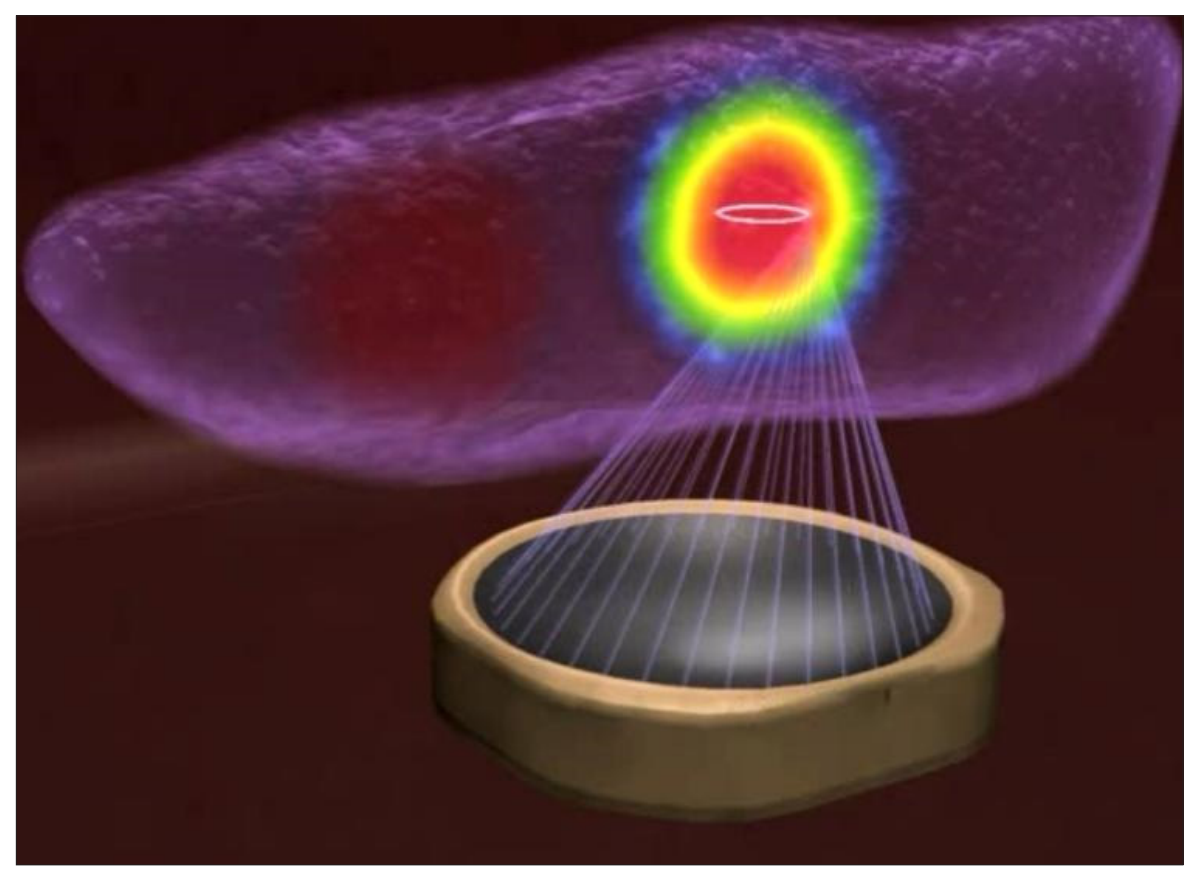

Figure 1. The transducer emits the therapeutic ultrasound beam to heat a focused point. (Figure courtesy of Profound Medical Corp - used with permission).

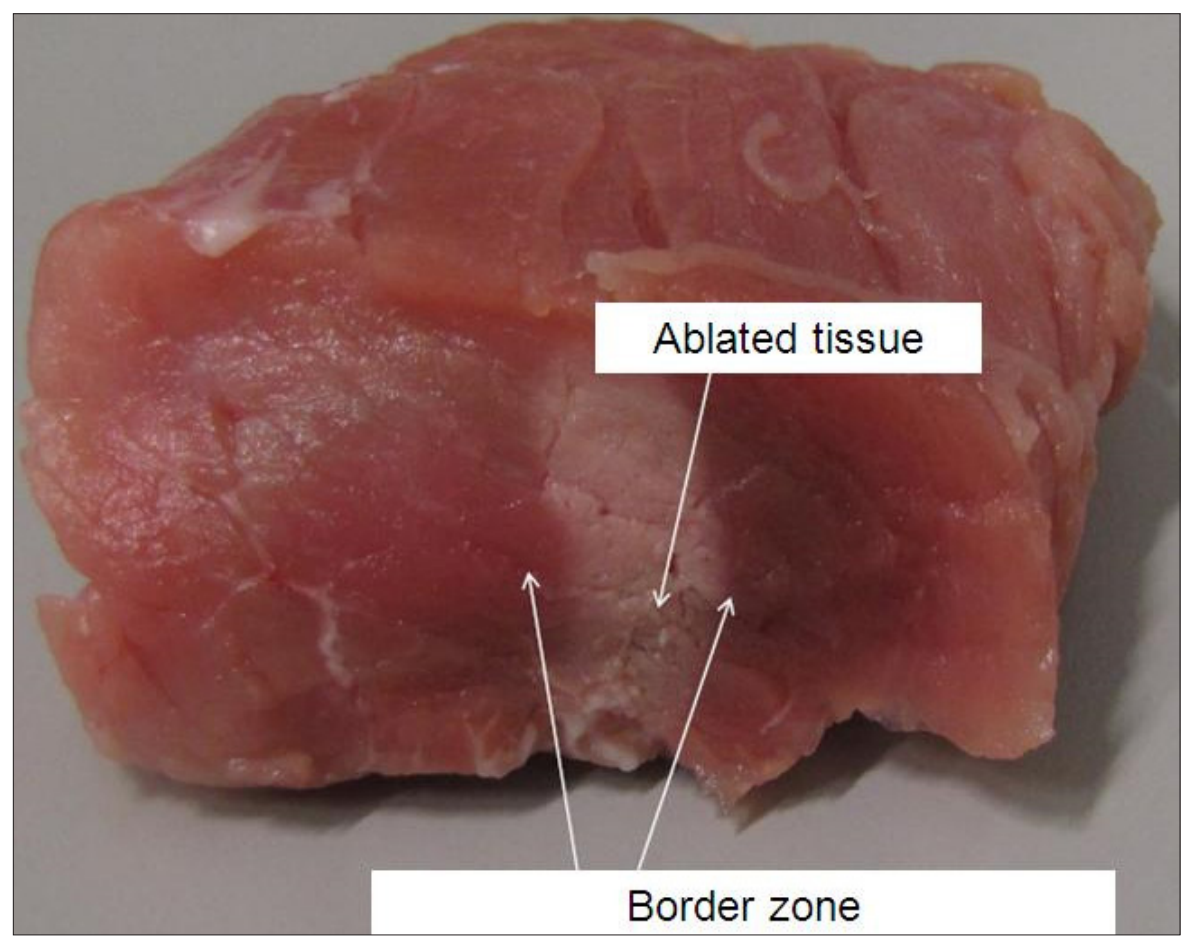

Figure 2. The immediate post-HIFU ablation image shows the HIFU-ablated region and the surrounding undamaged area.

(Figure courtesy of Holger Grüll, University of Cologne - used with permission). 
Table. Currently approved clinical applications of HIFU (96)

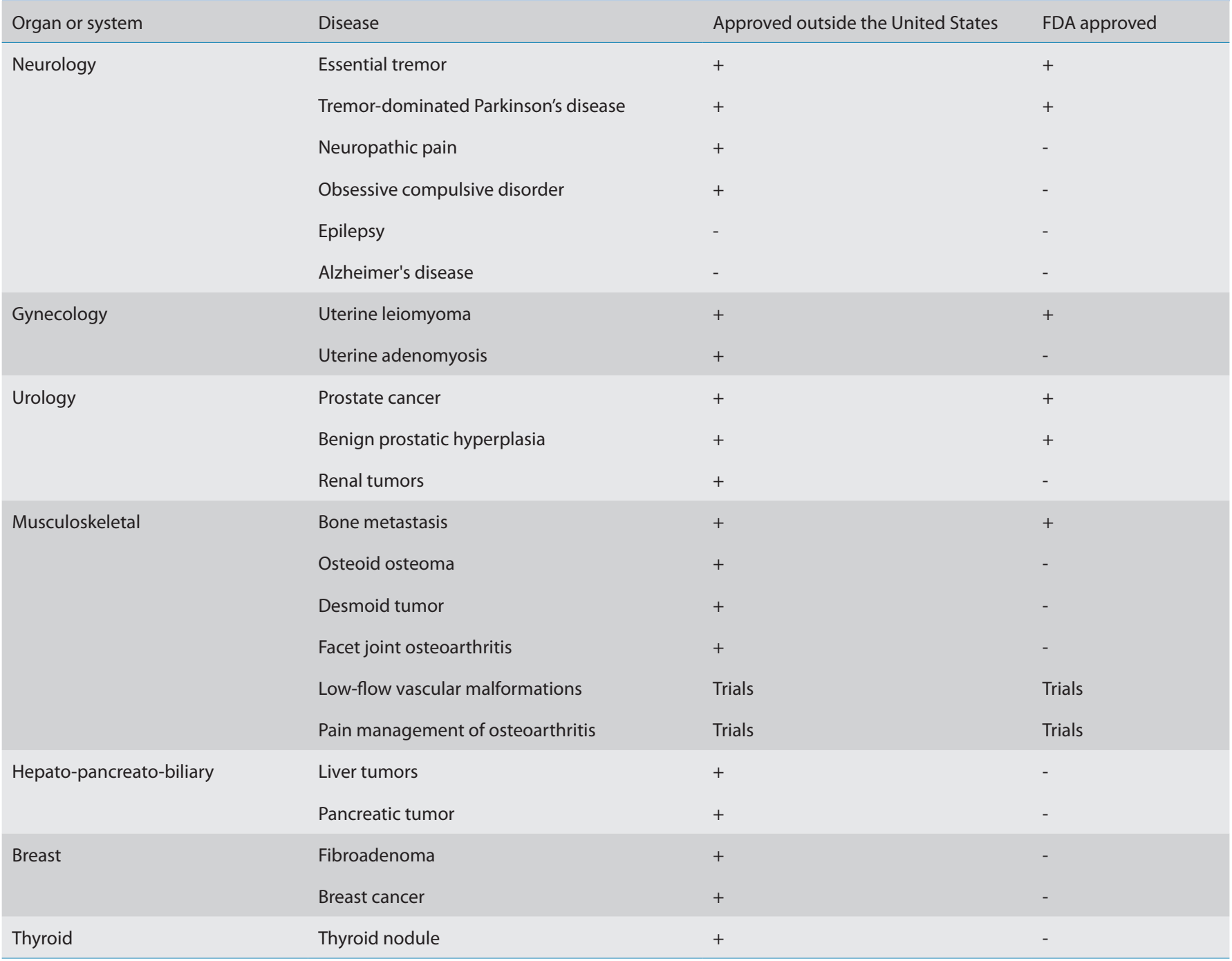

important role for predicting the immediate treatment outcome and are a critical safety feature to prevent excess heating of tissue in HIFU ablation (7).

\section{Emerging clinical HIFU applications}

\section{Neurology}

\section{Essential tremor}

Essential tremor (ET) is a frequent neurologic movement disorder in adults. The causes of ET and its mechanisms of pathogenesis are still unknown. Current available treatments are drug therapies, surgery, and deep brain stimulation. Beta-adrenergic blockers and primidone are the first-line treatment for ET. In order to impede abnormal nerve signals, radiofrequency ablation (RFA), gamma knife thalamotomy, deep brain stimulation, or stereotactic radiosurgery are considered as treatment options for drug-resistant ET patients. Recently, transcranial HIFU with MRI guidance has been used as a new surgical method applied to ET, and remarkable reduction of tremor score is increasingly reported (Fig. 7) (8). Findings from a multicenter randomized controlled clinical trial study led by Elias et al. (9) on 76 patients with moderate-to-severe ET treated by MRI-guided HIFU showed significant improvements of hand-tremor scores, disability and quality of life (e.g., $47 \%$ and $40 \%$ improvement at 3-month and 12-month assessment, respectively, compared with baseline), with a significant difference from patients who received a sham procedure (1\% improvement at 3-month assessment). Adverse events related to HIFU therapy included gait disturbance, numbness or paresthesia. Nonetheless, at 12-month fol- low-up, these adverse events remained in only $9 \%$ and $14 \%$ of the treated patient population, respectively. In another study, Meng et al. (10) demonstrated that HIFU thalamotomy was relatively effective and maintained durably clinical benefit within the first year of treatment, and the size of the initial lesion was significantly correlated with a 12-month outcome.

\section{Parkinson's disease}

Parkinson's disease (PD) is an age-related neurodegenerative disease of the central nervous system. Currently, the primary options for treatment of motor symptoms include drug therapy, radiofrequency lesioning and deep brain stimulation. HIFU was initially utilized to treat PD in the 1950s. At that time, it was necessary to remove bone fragments of the skull. The Fry brothers first investigated the possibility of utilizing fo- 


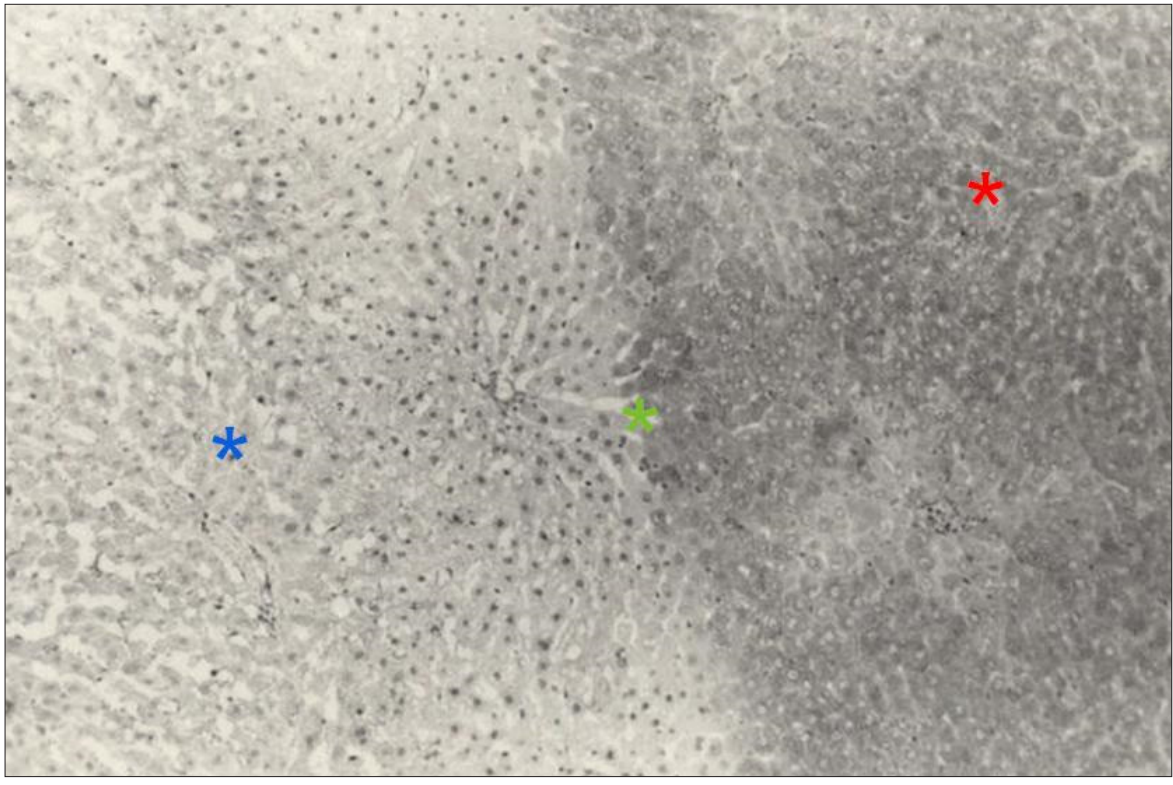

Figure 3. Figure 3. Histopathologic findings show the ablated region with irreversible cell damage comprised of deformed cells and pyknotic nuclei (blue asterisk), the borderline between the ablated and surrounding area with reversible cell damage (green asterisk), and the surrounding area with undamaged cells (red asterisk). (Figure courtesy of Lili Chen, Fox Chase Cancer Center - used with permission)

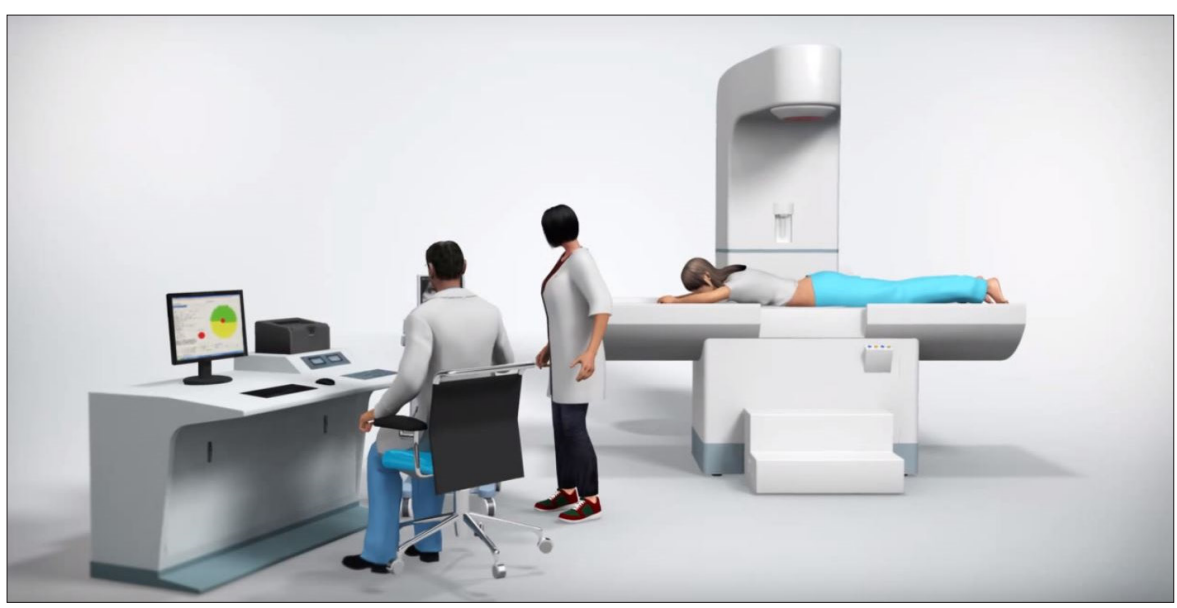

Figure 4. Ultrasound-guided HIFU system (Figure courtesy of Shenzhen Huikang Medical Apparatus Co., Ltd. - used with permission).

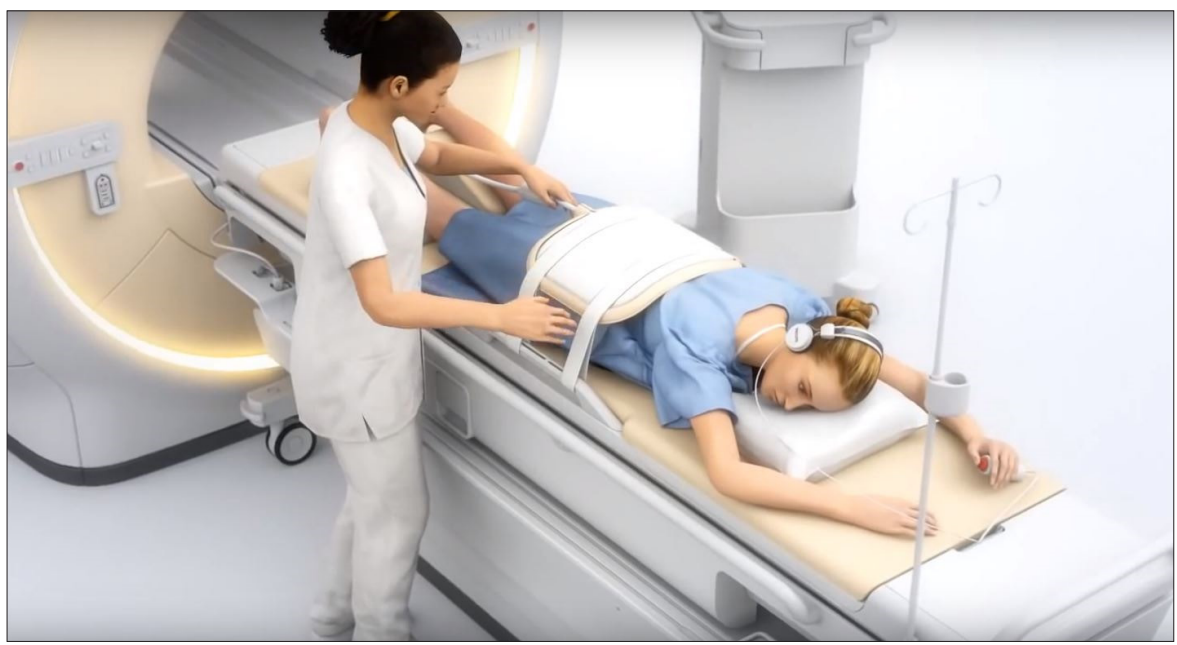

Figure 5. MRI-guided HIFU system (Figure courtesy of Profound Medical Corp - used with permission). cused ultrasound for the treatment of PD in $1960(6,11)$. Despite promising results, these early investigations did not gain acceptance due to the appearance of levodopa-resistance problem along with dyskinesia within a few years after treatment.

Based on the first report on the use of the MRI-guided HIFU pallidothalamic tractotomy in the treatment of 13 patients (first 4 patients as group 1 and remaining 9 patients as group 2) with PD, Magara et al. (12) reported that HIFU sonication was repeated up to 5 times higher in group 2 than in group 1 to obtain a higher volume of thermally ablated lesions, resulting in visibly ablated lesions on T2-weighted images. As a result, average improvement based on the Unified Parkinson's Disease Rating Scale before and 3-month after treatment was $7.6 \%$ in group 1 and $60.9 \%$ in group 2, suggesting that higher treatment intensities with several sonication pulses are most effective in generating therapeutic lesions. In a study by Zaaroor et al. (13) on patients with PD who underwent MRI-guided HIFU ventral intermediate nucleus thalamotomy to diminish medication-resistant tremor, the findings showed that post-ablation adverse events comprised of asthenia, gait ataxia, taste disturbances, unsteady feeling and hand ataxia, but these adverse events naturally resolved at 3-month follow-up. A recent study by lacopino et al. (14) on 4 patients who were the first series of patients treated with a transcranial HIFU thalamic system integrated with a 1.5T MRI machine showed that a simultaneous lightening of tremor severity was obtained without severe permanent side effects. A recent clinical trial study by Jung et al. (15) on 8 patients with PD undergoing unilateral MRI-guided HIFU pallidotomy revealed that baseline quality of life, unified PD rating scale and unified dyskinesia rating scale scores were significantly improved in comparison with 1-year follow-up scores. One patient suffered from an unusual contemporary dysarthria and grade III right motor hemiparesis.

\section{Neuropathic pain}

Neuropathic pain is a common form of the chronic pain correlated with nerve fiber dysfunction transmitting incorrect signals with minimal stimulation to the pain center. In a study by Jeanmonod et al. (16) on 12 patients with chronic therapy-resistant neuropathic pain who under- 


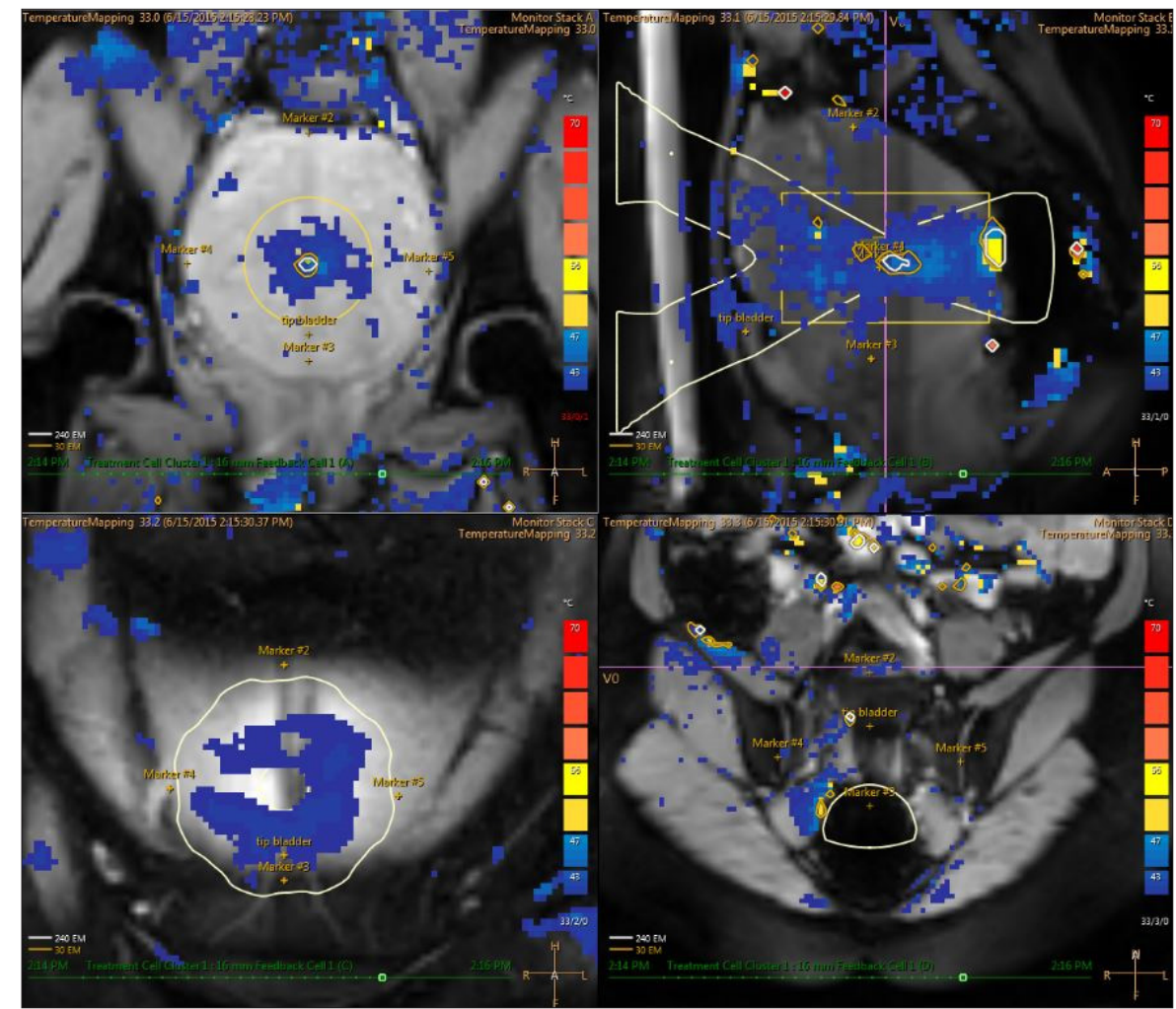

Figure 6. Real-time feedback temperature map of MRI-guided HIFU with the color scale during ablation therapy: upper left image shows coronal plane; upper right image shows sagittal plane; lower left image shows near field; lower right image shows far field.

went transcranial MRI-guided HIFU central lateral thalamotomies, the visual analog scale (VAS) pain score was significantly improved at 3-month and 12-month follow-up, with 6 patients experiencing simultaneous and persistent somatosensory improvements.

\section{Other potential neuro applications}

The blood-brain barrier is still one of the most significant limitations to treatments of central nervous system disorders such as neurodegenerative diseases, brain tumors, and psychiatric disorders. Under the guidance of MRI, HIFU is applied to pre-selected brain targets with sub-millimeter precision. Therefore, HIFU is a promising therapeutic method to increase permeability via blood-brain barrier disruption to benefit drug delivery to particular brain areas, hence improving the efficacy of drugs or other main therapeutic treatment options $(17,18)$. In addition, there are also many potential applications for neurologic disorders and neuromodulation, still under clinical trials or pre-clinical investigations such as Alzheimer's disease, obsessive compulsive disorder and epilepsy (19-24).

\section{Gynecology}

Uterine leiomyomas and adenomyosis

Adenomyosis and uterine leiomyomas are two common benign gynecologic diseases that cause a significant negative effect on the quality of life of reproductive-aged women. Symptoms related to these diseases vary depending on their size and location, but the main symptoms are bulk effect and abnormal uterine bleeding, constipation, urinary disorders, and infertility (25-28). Conventional surgical treatment options for symptomatic uterine leiomyomas and adenomyosis are myomectomy and hysterectomy, which are still preferred by gynecologists. Recently, newer less invasive treatment modalities such as uterine arterial embolization, ultrasound-guided HIFU, and MRI-guided HIFU are increasingly being exploited for the treatment of symptomatic leiomyomas and adenomyosis (Fig. 8) (29-31).

The latest studies demonstrated the ability of HIFU to decrease the volume of leiomyomas and adenomyosis and its correlation with the nonperfused volume of the tumor simultaneously after treatment (32-35). In two recent studies led by Keserci et al. $(34,35)$, the findings suggested that an nonperfused volume $\geq 90 \%$ is attainable in MRI-guided HIFU treatment of both adenomyosis and uterine leiomyomas without trading off the safety of patients. Furthermore, current achievements in HIFU treatments have also demonstrated that symptoms are significantly improved in terms of pain, bulk-related and menstrual symptoms, as compared with the outcome of conventional surgery (29-33). Although HIFU is a minimally-invasive procedure, there are still some common and severe complications which need careful consideration: abnormal vaginal discharge, acute kidney failure, bowel perforation, cystitis, deep vein thrombosis, erythema on the skin, fever, hematuria, hydronephrosis, hyperpyrexia, intrauterine infection, leg pain, nausea, numbness, pelvic pain, pubic symphysis injury, sacrococcygeal pain, sciatic nerve injury, skin burns, skin blisters, urinary retention, and thrombocytopenia $(36,37)$.

\section{Urology}

Prostate cancer and benign prostatic hyperplasia

Benign prostatic hyperplasia (BPH), the most common benign disease, degrades men's quality of life. The current therapeutic options for BPH are very abundant and include medication, transurethral microwave thermotherapy, transurethral incision of the prostate, transurethral resection of the prostate, transurethral needle ablation, laser therapy, embolization, open or robot-assisted prostatectomy, and HIFU (38). Prostate cancer is the most common malignant tumor among men. The main treatments for prostate cancer are radical prostatectomy and radiotherapy, but recurrence rate of these options after 5 years of treatment is still 20\%-50\% (39).

As findings have shown in some previous studies, transrectal ultrasonography-guided HIFU is considered as a novel potential minimally-invasive treatment for localized prostate cancer and benign prostatic hyperplasia and recommended for low- to intermediate-risk prostate cancer patients (Fig. 9) (40-43). A study by Ahmed et al. (44) reported that patients with unifocal and multifocal prostate cancer who underwent transrectal HIFU ablation had no evidence of recurrence on MRI at 12-month post-treatment follow-up. However, recurrent cancer was seen in more than $20 \%$ of the patients who underwent rebiopsy. 


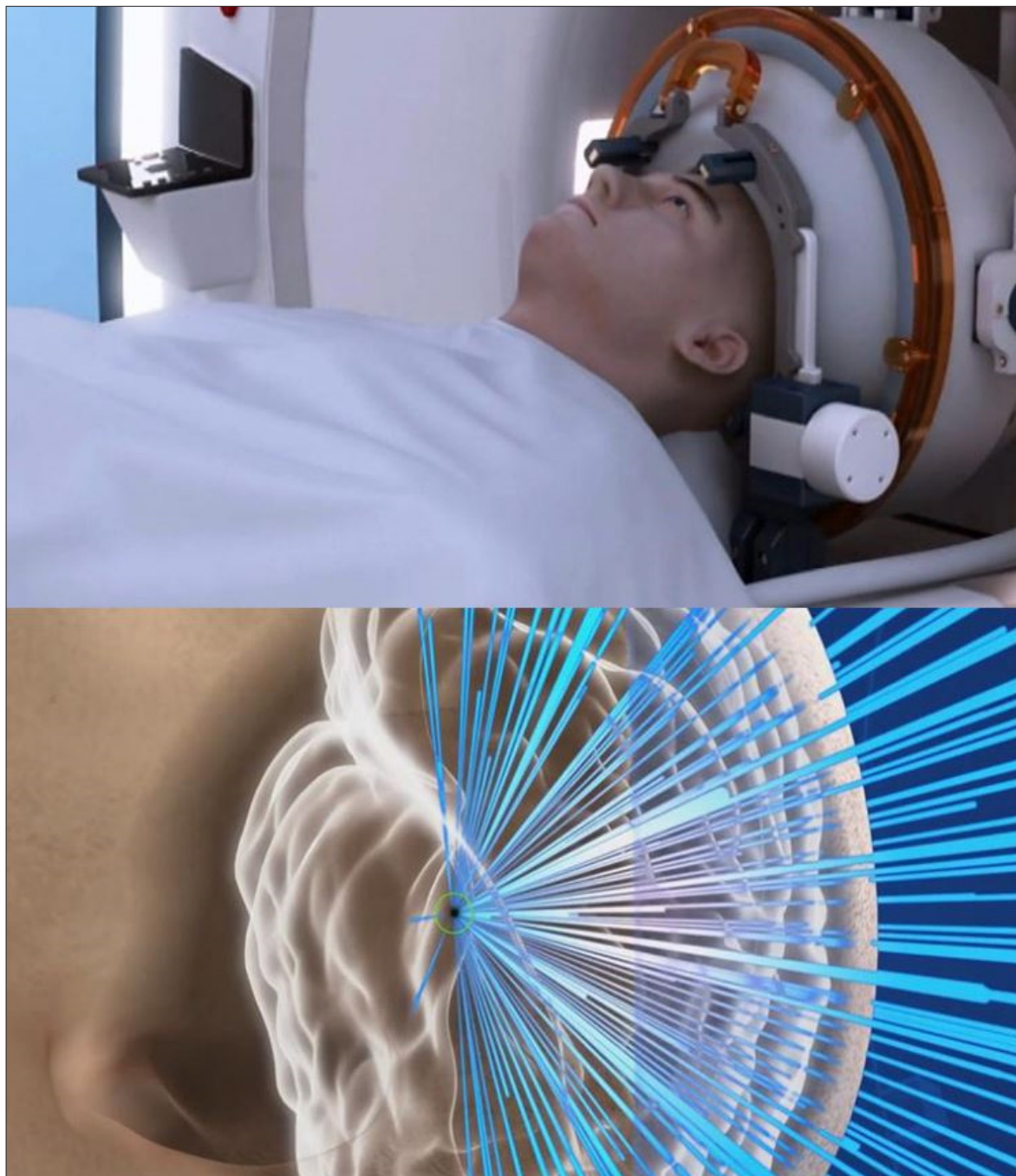

Figure 7. MRI-guided HIFU ablation for the brain with the ultrasound beam focused to the thalamus (Figure courtesy of Insightec Ltd. - used with permission).

Therefore, further follow-up is necessary to better understand long-term treatment outcomes after transrectal ultrasonography-guided HIFU therapy.

Transrectal or transurethral HIFU combined with MRI and thermometry with real-time temperature feedback within the gland during procedure provides (i) more precise localization of tumors to minimize damage to prostatic and peri-prostatic functional structures and (ii) real-time monitoring to allow continuous adjustment of treatment parameters according to the need (Figs. 10 and 11). In an early study led by Napoli et al. (45), patients with unifocal prostate cancer were treated with transrectal MRI-guided HIFU, and the preliminary findings demonstrated that erectile function and urinary continence improved effectively post-treatment. Nevertheless, adverse events such as acute urinary retention or severe rectal wall perforation occurred. A recent transurethral MRI-guided HIFU study by Chin et al. (46) showed that international index of erectile function, international prostate symptom, quality of life, and serum prostate-specific antigen were significantly improved at 12-month follow-up. Adverse events related to the treatment included acute urinary retention, epididymitis, hematuria, and urinary tract infection.

A study by $\mathrm{Xu}$ et al. (47) on 262 patients with BPH undergoing transrectal ultrasound-guided HIFU ablative therapy showed that quality of life score, international prostate symptom score, and prostatic volume significantly ameliorated, while the peak uroflow rate increased evidently in one to three years of follow-up. In another study by Lu et al. (48) on 150 patients with $\mathrm{BPH}$ undergoing transrectal ultra- sound-guided HIFU treatment, quality of life improved and international prostate symptom score declined significantly at 1-, 2-, 6and 12-month post-treatment. Maximum urine flow rate and prostatic volume were significantly improved at 12 months after treatment. Adverse events related to this treatment were mild hematuria and epididymitis, retrograde ejaculation, short-term hematospermia, and urethro-rectal fistula. These studies demonstrate that treatment of BPH by HIFU is relatively safe and effective (44-48).

\section{Renal tumors}

According to European Association of Urology guidelines, HIFU is recommended in patients who have kidney tumors $\leq 4 \mathrm{~cm}$ and are unfit for surgery (49). Several studies, which have investigated HIFU in the treatment of both primary and metastatic renal tumors (50-52), reported that $90 \%$ of patients experienced effective pain control simultaneously post-HIFU treatment (41-43). However, several negative factors such as subcutaneous and perinephric fat thickness and the tumor location relative to the ribs, affected this method (53). Higher ultrasonic power is crucial to make up for the energy loss due to absorption by subcutaneous and perinephric fat, consequently increasing the risk of prefocal tissue burning (54).

A phase I study comprising 17 patients with non-metastatic renal tumors undergoing ultrasound-guided HIFU ablation showed that HIFU can achieve tumor ablation in two-thirds of the patients with mean tumor shrinkage of $30 \%$, which is reassuring evidence of successful ablation (55). Another study by Wu et al. (56) on 13 patients with kidney cancer undergoing ultrasound-guided HIFU therapy (group 1 including 7 patients who died during follow-up; group 2 including 6 patients who were still alive) showed that the median survival time was 14.1 months in group 1 and 18.5 months in group 2 .

\section{Musculoskeletal}

Bone metastasis

Several clinical reports proved that MRI-guided HIFU is efficacious in the palliative treatment of painful bone tumors (Fig. 12) (57-59). The main aim of this approach is to achieve periosteal denervation and tumor debulking, which will improve symptom relief and quality of life. 


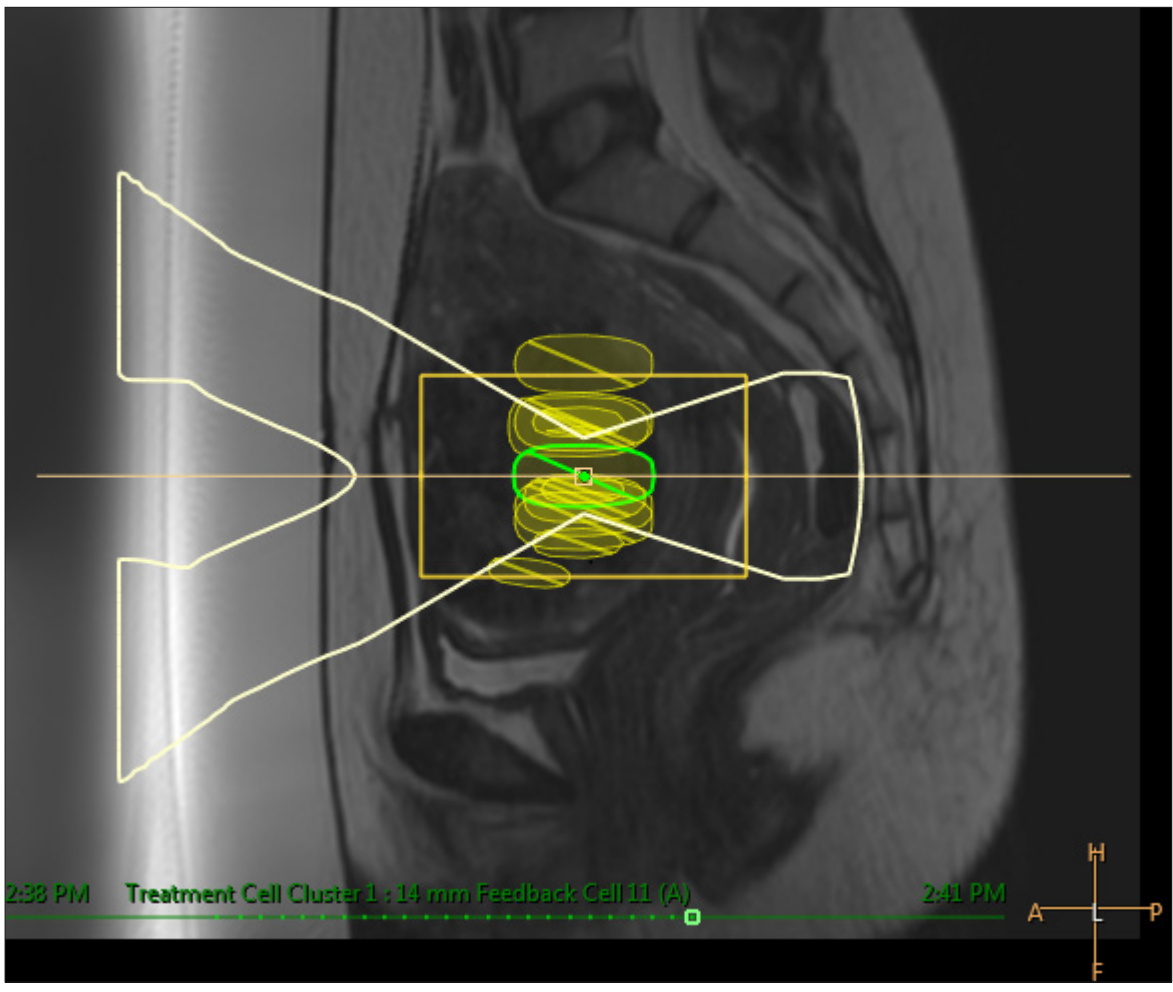

Figure 8. Sagittal T2-weighted image shows ultrasound beam under the guidance of MRI targeted to treatment cell located inside the uterine fibroid.

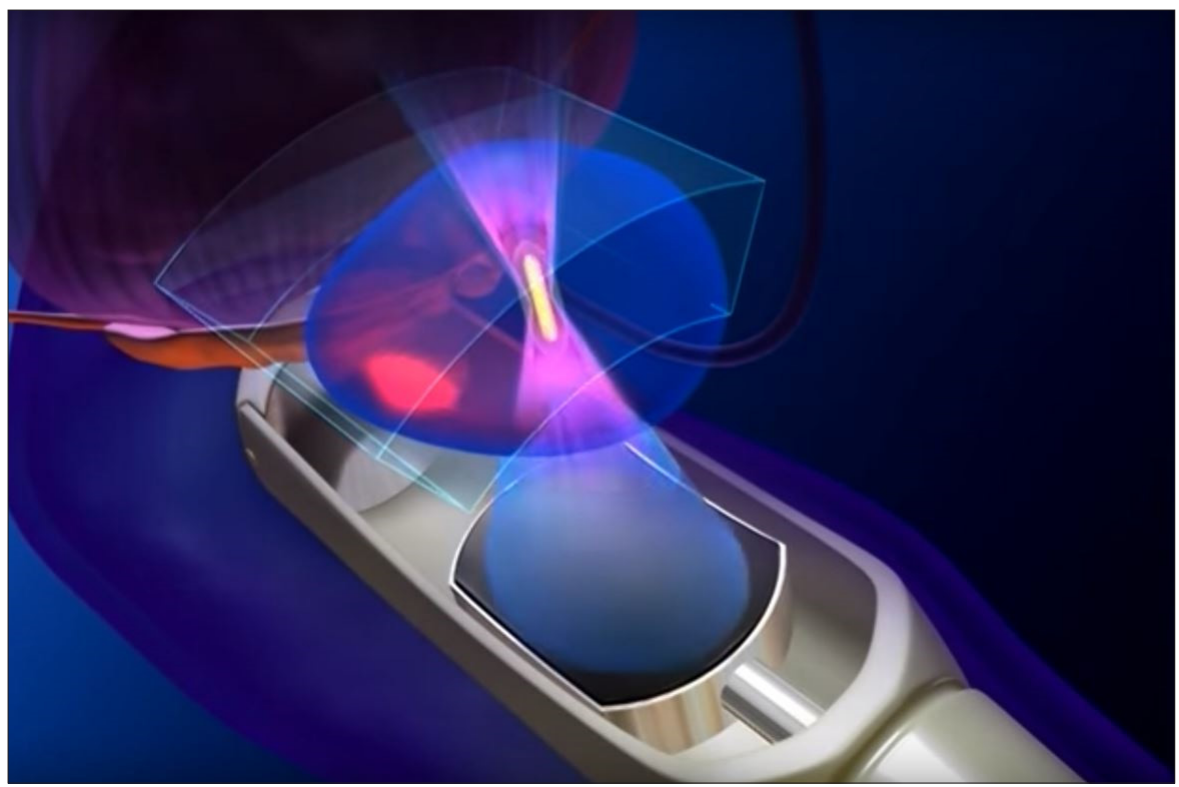

Figure 9. Transrectal ultrasound-guided HIFU ablation of the prostate with transrectal transducer (Figure courtesy of SonoCare Medical - used with permission).

Furthermore, remineralization of spongious bone and reduction of lesion size are also observed (60).

A multicenter study by Harding et al. (57) on 18 patients suffering from pain due to bone metastases who underwent MRI-guided HIFU treatment showed that $53 \%$ of patients had significantly improved
In a trial study by Hurwitz et al. (61) on 147 patients with painful bone metastases (112 underwent MRI-guided HIFU and 35 were assigned to placebo treatment), the findings revealed that the response rate of the MRI-guided HIFU group was significantly higher than that of the placebo group $(P<0.05)$. In addition, at 3-month follow-up, the secondary endpoints assessing worst score and quality of life score of the MRI-guided HIFU group were significantly better than those of the placebo group $(P<$ 0.05 ). Of the patients, $32.1 \%$ reported pain during the ablation procedure. Adverse events included pathologic fractures in 2 patients, third-degree skin burn in one patient, and neuropathy in one patient. Thus, MRI-guided HIFU is a safe and effective alternative treatment for relieving metastatic bone pain.

\section{Osteoid osteoma}

Osteoid osteoma, which is a benign tumor but negatively affects both children and young adults, produces severe pain that often appears at night and is relieved by nonsteroidal anti-inflammatory drugs. When the pain becomes more severe and less responsive to medication, RFA is regarded as an efficacious therapeutic option (59-63). The main aim of surgical treatment or minimally invasive RFA is to destroy the nidus of osteoid osteoma and adjacent periosteal nerves (64).

In terms of a minimally-invasive approach, bleeding, osteomyelitis, exposure to anesthesia, and fast recovery time, HIFU is superior to RFA or conventional surgery. In a study by Napoli et al. (65), 45 osteoid osteoma patients who underwent MRI-guided HIFU were successfully treated without complications. The median visual analogue scale (VAS) pain score reduced significantly from 8 prior to treatment to 0 at 1-week and at 1-, 6-, 12-, 24-, and 36-month follow-ups. Furthermore, the VAS score for pain deteriorating sleep and physical activities reduced significantly to 0 after 1 month of treatment and persisted firmly during the follow-up period. A recent pilot study led by Sharma et al. (66) revealed that the outcomes were not significantly different between HIFU and RFA for pediatric patients. Thus, HIFU is an effective option with promising clinical efficacy and safety as part of a routine strategy for the treatment of osteoid osteoma. 


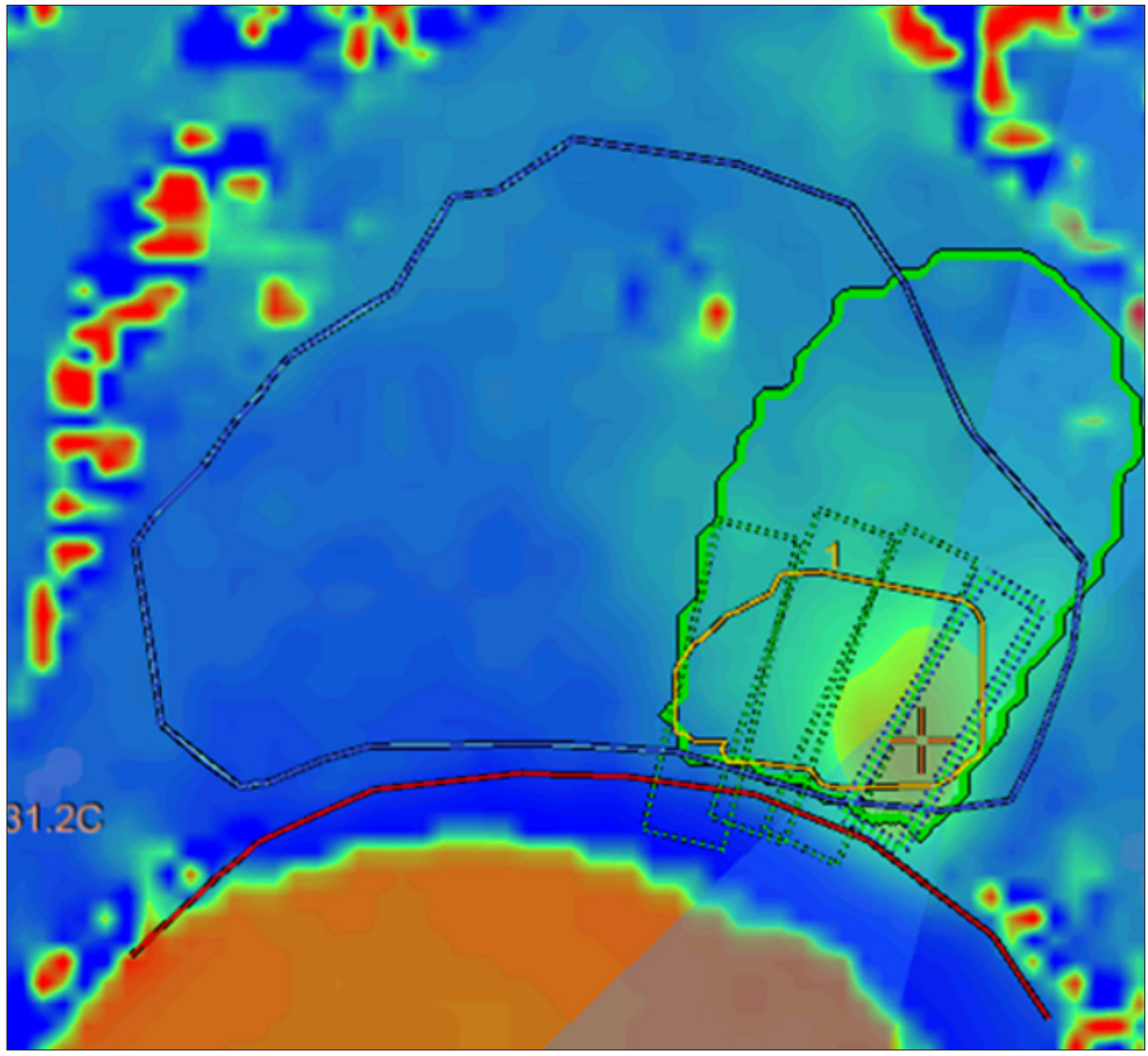

Figure 10. Transrectal MRI-guided HIFU ablation of the prostate with transrectal transducer along with temperature mapping during the ablation procedure (Figure courtesy of Insightec Ltd. - used with permission).

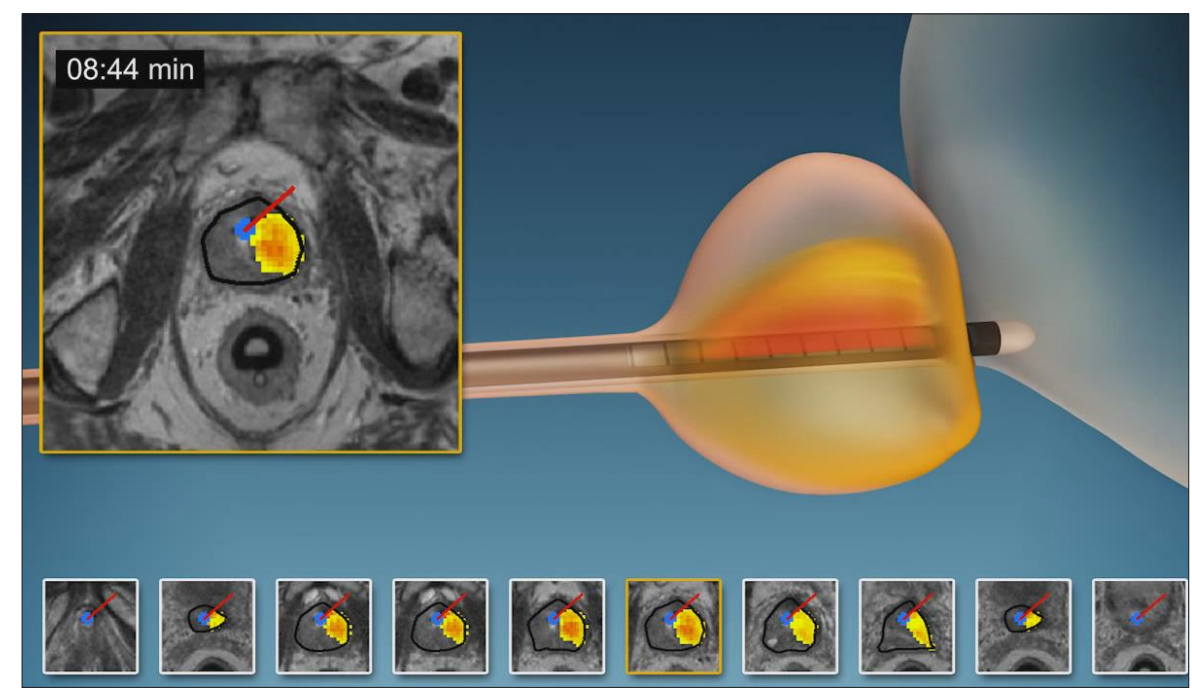

Figure 11. Transurethral MRI-guided HIFU ablation of the prostate with transurethral transducer along with temperature mapping during the ablation procedure (Figure courtesy of Profound Medical Corp - used with permission).

Other potential musculoskeletal applications

The use of HIFU in the treatment of musculoskeletal conditions has also been extended to other conditions, such as lowflow vascular malformations, extra-abdominal desmoid tumors, and osteoarthritis (67). In a previous study by Ghanouni et al. (68), the results revealed that MRI-guided HIFU was considered as an effective treatment without severe complications of low-flow vascular malformations. After 9 months of follow-up, the mean pain score of 5 patients was reduced significantly from $8.4 \pm 1.5$ to $1.6 \pm 2.2(P<0.05)$. Furthermore, the median size of lesions was also reduced significantly from $8.2 \mathrm{~mL}$ to $0 \mathrm{~mL}(P<0.05)$.

Osteoarthritis is the most common cause of pain among the elderly. Currently, HIFU offers an alternative option to take into consideration in cases of osteoarthritis. Findings in a recent study on 6 knee osteoarthritis patients undergoing MRI-guided HIFU showed that after 6 months of follow-up, mean VAS decline was $72.6 \%$. Pressure pain thresholds were significantly improved from $358 \mathrm{kpa}$ to $534 \mathrm{kpa}(P<$ $0.05)$, and treatment was effective in all 6 cases without any serious side-effects (69). In another study on 18 patients with facet joint osteoarthritis undergoing MRI-guided HIFU, the results revealed that there were no major complications during treatment and follow-up period. Pain numerical rating scale, Oswestry disability questionnaire, and Brief Pain Inventory of the patients were all improved in comparison with the baseline (70).

For desmoid tumor, HIFU has shown a potential role without severe side-effects. Results in a multicenter study manifested that after MRI-guided HIFU, median tumor volume reduced significantly by up to $63 \%$. Average pain score also significantly decreased from $6 \pm 2.3$ to $1.3 \pm 2$ (71).

\section{Hepato-pancreato-biliary}

\section{Liver tumors}

Surgical resection is currently the gold treatment for liver cancer. In the last few decades, the therapeutic concept of both primary and secondary liver tumors has shifted from invasive open surgical procedures to minimally invasive image-guided tumor ablation techniques $(72,73)$. Visioli et al. (72), who performed the first liver tumor ablations using ultrasound-guided HIFU, reported that the ablations were effective, with the only side effects being transient pain and skin burns, but the authors also stated the difficulties in visualizing the tumor during ablation due to the limitations of ultrasound guidance. However, none of these studies attempted to ablate tumors entirely. Another ultrasound-guided HIFU study on 49 patients with unresectable liver cancer reported a technical success rate of $79.5 \%$ and a mortality rate of $2 \%$; complications related to the treatment included skin burns, pain, fever, and mild impairment of liver or renal function, and thus it was demonstrated that HIFU treatment was effective for patients with inoperable hepa- 


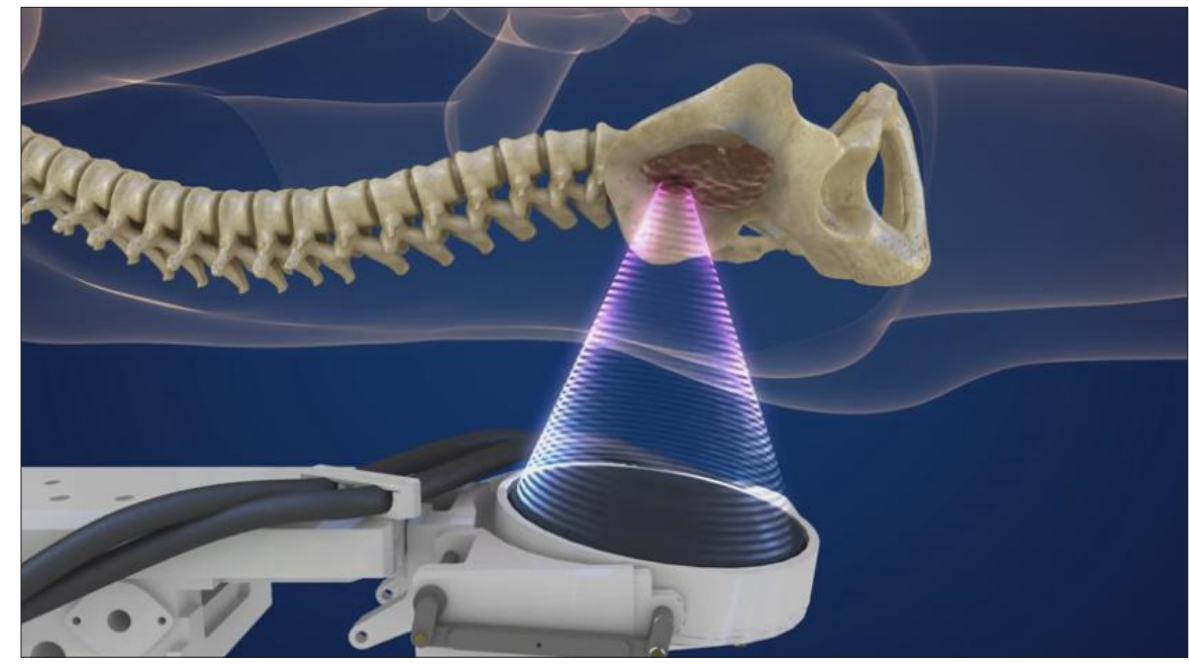

Figure 12. HIFU ablation of the bone with the ultrasound beam focused to the bone tumor so as to eradicate nerves inside the lesion (Figure courtesy of Insightec Ltd. - used with permission).

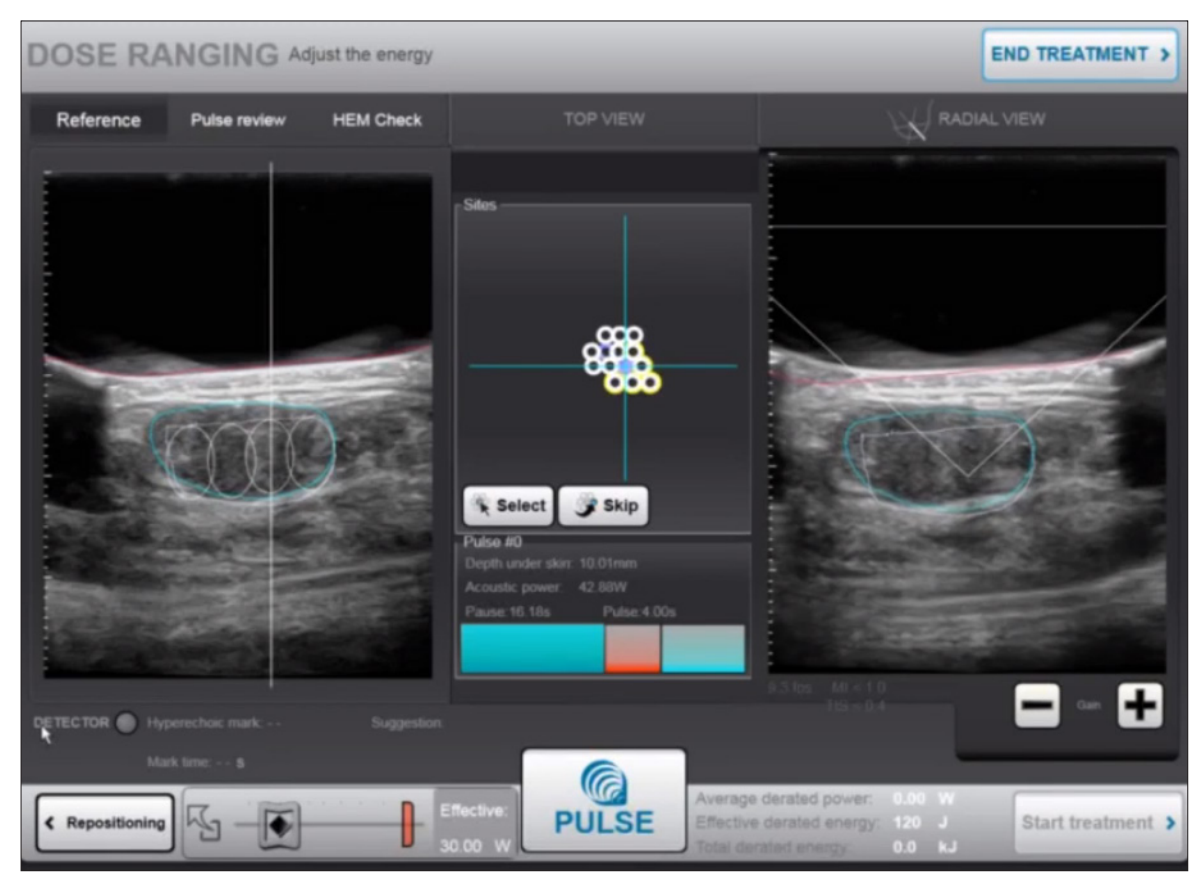

Figure 13. HIFU ablation of the breast tumor (Figure courtesy of Theraclion - used with permission).

tocellular carcinoma (74). A recent clinical study led by Chen et al. (75) investigated the feasibility and effectiveness of ultrasound-guided HIFU treatment in patients with unresectable liver cancer (116 primary liver cancer patients and 71 metastatic liver cancer patients). The authors demonstrated that success rates in the left and right lobes were $90.5 \%$ and $64.1 \%$, respectively.

Okada et al. (76) reported that clinical MRI-guided HIFU treatment of a patient with a hepatocellular carcinoma of $15 \mathrm{~mm}$ in diameter in the left lateral liver segment, avoiding the ribs by using a respiratory monitoring system, was feasible. Their patients with inoperable pancreatic cancer revealed that HIFU might be a probable therapeutic treatment option for palliative treatment and pain relief of pancreatic cancer without a negative impact on the exocrine or endocrine functions (77-81).

A clinical study of ultrasound-guided HIFU comprising 89 advanced pancreatic cancer patients undergoing HIFU treatment showed the median survival rates of stage II, III and IV cancer as 26.0 months, 11.2 months, and 5.4 months, respectively. Pain was reduced significantly in $80.6 \%$ of patients (80). A report by Wu et al. (81) on 8 advanced-stage pancreatic cancer patients revealed that prior severe back pain vanished after ultrasound-guided HIFU treatment, and no adverse events were noticed. In another study on 7 patients with unresectable pancreatic cancer who underwent MRI-guided HIFU, the treatments were successful without severe adverse events on 6 patients with pancreatic cancer (one case excluded due to the appearance of the transverse colon between the transducer and targeted tumor). VAS was reduced significantly from $7 \pm 1$ at baseline to $3 \pm 1$ one week post-treatment $(P<0.05)$. Immediate mean nonperfused volume was $60 \% \pm 5 \%$. During the follow-up, 5 patients had no recurrence of the tumor (82). Thus, palliation of pain related to pancreatic cancer may be achieved by HIFU therapy.

\section{Breast}

Compared with other treatment options such as mastectomy or tumorectomy, HIFU is an optimal breast-conserving therapy since it does not result in bleeding, wound pain, impaired wound healing or scarring after the treatment. HIFU is utilized for breast cancer treatment, and its rate of technical success ranged from $20 \%$ to $100 \%$, relying on patient selection and imaging-guided technique and ablation protocol (Fig. 13) (83-85).

An early randomized clinical trial study by Wu et al. (86) on 48 patients with breast cancer who underwent ultrasound-guided HIFU ablation reported that the HIFU-treated cancer region had fully coagulative necrosis and tumor vascularity was completely blocked without severe complications. Furthermore, immunohistochemical staining showed that PCNA, MMP-9, and CD44v6 were not detected within the ablated tumor. 


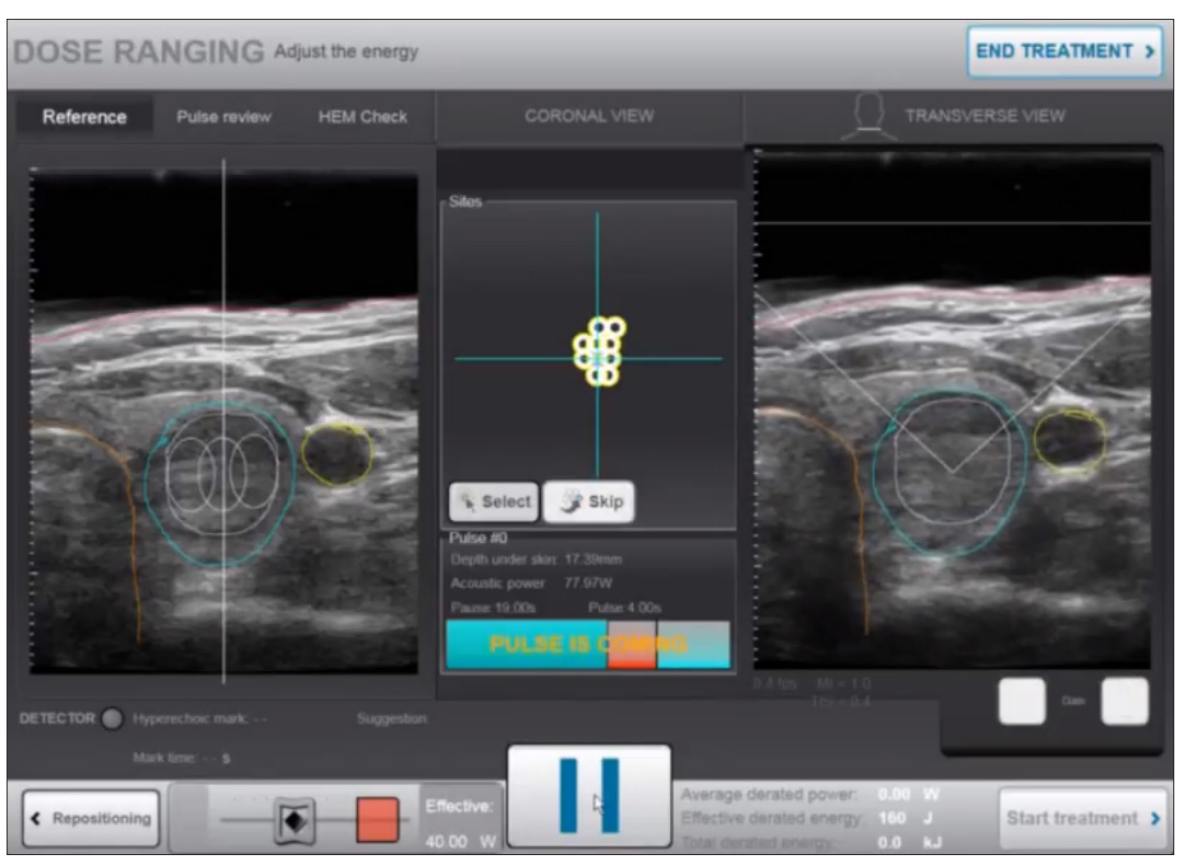

Figure 14. HIFU ablation of the thyroid nodule (Figure courtesy of Theraclion - used with permission).

The histopathologic findings of a study by Furusawa et al. (87) carried out on 31 patients with breast cancer undergoing MRI-guided HIFU and subsequent mastectomy showed mean percentage of breast tumor necrosis as $96.9 \% \pm 4 \%(78 \%-100 \%)$, with $53.5 \%$ of patients having complete necrosis, and only $10.7 \%$ patients having $<95 \%$ necrosis. In a study by Guan et al. (88) on 25 breast cancer patients undergoing ultrasound-guided HIFU, 12-month follow-up findings showed no local recurrence or distant metastatic lesion. Histologic features of breast tissue using hematoxylin-eosin staining showed that HIFU resulted in comprehensively coagulative necrosis in the tumor tissues and vascularities. In addition, biotinylated-ulex europaeus agglutinin I staining of the targeted lesion sample was negative. A clinical trial study by Peek et al. (89) on 51 patients with symptomatic fibroadenomata undergoing ultrasound-guided HIFU showed that volume reduction of breast tumors was $43.2 \%$ at 12 months post-treatment. Skin hyperpigmentation was a common adverse effect related to this therapy, but it resolved naturally without any interventions. A recent study by Kovatcheva et al. (90) on 42 patients with breast fibroadenoma undergoing ultrasound-guided HIFU showed that at 12-month follow-up, the mean volume reduction of tumors was $72.5 \%$. Adverse effects related to treatment were skin burn, skin blister, and hyperpigmentation at the treated area.

\section{Thyroid}

Thyroid nodules are common problematic conditions unveiled by clinical palpation (5\% of cases) and high-resolution ultrasound imaging (60\%). Fine-needle aspiration cytology is usually exploited to investigate the histopathology of these nodules as the main evidence for selecting the corresponding treatment $(91,92)$. For symptomatic or growing benign thyroid nodules, surgical resection is traditionally considered as the primary treatment. Nevertheless, surgery carries some risks of anesthesia, voice disorder, hypothyroidism, bleeding, and infection. This has led to the appearance of less invasive treatment options including percutaneous ethanol injection, laser ablation therapy, RFA and HIFU (Fig. 14) (91-93). In a comparative study by Lang et al. (94), 22 thyroid nodule patients adopted ultrasound-guided HIFU versus 22 patients with thyroid nodules who underwent active surveillance. The results showed that the 12-month mean volume reduction in the HIFU group was significant, whereas this was not the case in the surveillance group. Another study by Lang et al. (95) on 108 patients with thyroid nodules showed that after treatment, the mean volume ratio was reduced significantly at $3,6,12,18$, and 24 months. Furthermore, the baseline VAS was alleviated gradually during 6,12 , and 24 months of follow-up. Therefore, HIFU ablation of symptomatic benign thyroid nodules shows promising efficacy and is a safe treatment option.

\section{Conclusion}

HIFU is an emerging alternative treatment option for various benign and malignant diseases. It is a novel, minimally invasive and innovative therapeutic method for patients who are ineligible for surgery or have contraindications to surgery. The results of HIFU introduced in this article are primarily propitious. Therefore, we believe that further randomized clinical trial studies should be launched to validate and compare the safety and effectiveness of HIFU with other current available treatments in various diseases.

\section{Conflict of interest disclosure}

The authors declared no conflicts of interest.

\section{References}

1. Mason TJ. Therapeutic ultrasound an overview. Ultrason Sonochem 2011; 18:847-852. [CrossRef]

2. Haar GT, Coussios C. High intensity focused ultrasound: physical principles and devices. Int J Hyperthermia 2007; 23:89-104. [CrossRef]

3. Wood RW, Loomis AL. The physical and biological effects of high frequency sound-waves of great intensity. Phil Mag 1927; 4:7-14. [CrossRef]

4. Lynn JG, Zwemer RL, Chick AJ. The biological application of focused ultrasonic waves. Science 1942; 96:119-120 [CrossRef]

5. Fry WJ, Mosberg WH Jr, Barnard JW, Fry FJ. Production of focal destructive lesions in the central nervous system with ultrasound. J Neurosurg 1954; 11:471-478. [CrossRef]

6. Vaezy S, Shi X, Martin RW, et al. Real-time visualization of high-intensity focused ultrasound treatment using ultrasound imaging. Ultrasound Med Biol 2001; 27:33-42 [CrossRef]

7. Kim YS. Advances in MR image-guided high-intensity focused ultrasound therapy. Int J Hyperthermia 2015; 31:225-232. [CrossRef]

8. Elias WJ, Huss D, Voss T, et al. A pilot study of focused ultrasound thalamotomy for essential tremor. N Engl J Med 2013;369:640-648. [CrossRef]

9. Elias WJ, Lipsman N, Ondo WG, et al. A Randomized Trial of Focused Ultrasound Thalamotomy for Essential Tremor. N Engl J Med 2016; 375:730-739. [CrossRef]

10. Meng Y, Solomon B, Boutet A, et al. Magnetic resonance-guided focused ultrasound thalamotomy for treatment of essential tremor: A 2-year outcome study. Mov Disord 2018; 33:1647-1650. [CrossRef]

11. Fry WJ, Barnard JW, Fry EJ, Krumins RF, Brennan JF. Ultrasonic lesions in the mammalian central nervous system. Science 1955; 122:517-518. [CrossRef]

12. Magara $A$, Bühler $R$, Moser $D$, Kowalski $M$, Pourtehrani $P$, Jeanmonod D. First experience with MR-guided focused ultrasound in the treatment of Parkinson's disease. J Ther Ultrasound 2014; 31:11. [CrossRef]

13. Zaaroor M, Sinai A, Goldsher D, Eran A, Nassar M, Schlesinger I. Magnetic resonance-guided focused ultrasound thalamotomy for tremor: a report of 30 Parkinson's disease and essential tremor cases. J Neurosurg 2018; 128:202-210. [CrossRef] 
14. lacopino DG, Gagliardo C, Giugno A, et al. Preliminary experience with a transcranial magnetic resonance-guided focused ultrasound surgery system integrated with a 1.5-T MRI unit in a series of patients with essential tremor and Parkinson's disease. Neurosurg Focus 2018; 44:E7. [CrossRef]

15. Jung NY, Park CK, Kim M, Lee PH, Sohn YH, Chang JW. The efficacy and limits of magnetic resonance-guided focused ultrasound pallidotomy for Parkinson's disease: a Phase I clinical trial. J Neurosurg 2018; 10:1-9. [CrossRef]

16. Jeanmonod D, Werner B, Morel A, et al. Transcranial magnetic resonance imaging-guided focused ultrasound: noninvasive central lateral thalamotomy for chronic neuropathic pain. Neurosurg Focus 2012; 32:E1. [CrossRef]

17. Burgess A, Shah K, Hough O, et al. Focused ultrasound-mediated drug delivery through the blood-brain barrier. Expert Rev Neurother 2015; 15:477-491. [CrossRef]

18. Timbie KF, Mead BP, Price RJ, et al. Drug and gene delivery across the blood-brain barrier with focused ultrasound. J Control Release 2015; 219:61-75. [CrossRef]

19. Burgess A, Shah K, Hough O, et al. Focused ultrasound-mediated drug delivery through the blood-brain barrier. Expert Rev Neurother 2015; 15:477-491. [CrossRef]

20. Timbie KF, Mead BP, Price RJ, et al. Drug and gene delivery across the blood-brain barrier with focused ultrasound. J Control Release 2015; 219:61-75. [CrossRef]

21. Jung HH, Chang WS, Kim SJ, Kim CH, Chang JW. The potential usefulness of magnetic resonance guided focused ultrasound for obsessive compulsive disorders. J Korean Neurosurg Soc 2018; 61:427-433. [CrossRef]

22. Souza RMDCE, da Silva ICS, Delgado ABT, da Silva PHV, Costa VRX. Focused ultrasound and Alzheimer's disease A systematic review. Dement Neuropsychol 2018; 12:353-359. [CrossRef]

23. Krishna V, Sammartino F, Rezai A. A review of the current therapies, challenges, and future directions of transcranial focused ultrasound technology: advances in diagnosis and treatment. JAMA Neurol 2018; 75:246-254. [CrossRef]

24. Kubanek J. Neuromodulation with transcranial focused ultrasound. Neurosurg Focus 2018; 44:E14. [CrossRef]

25. Baird DD, Dunson DB, Hill MC, Cousins D, Schectman JM. High cumulative incidence of uterine leiomyoma in black and white women: ultrasound evidence. Am J Obstet Gynecol 2003; 188:100-107. [CrossRef]

26. Pritts EA, Parker WH, Olive DL. Fibroids and infertility: an updated systematic review of the evidence. Fertil Steril 2009; 91:1215-1223. [CrossRef]1

27. Azziz R. Adenomyosis: current perspectives. Obstet Gynecol Clin North Am 1989; 16:221235.

28. Vercellini P, Ragni G, Trespidi L, Oldani S, Panazza S, Crosignani PG. Adenomyosis: a déjà vu? Obstet Gynecol Surv 1993; 48:789_ 794. [CrossRef]

29. Masciocchi C, Arrigoni F, Ferrari F, et al. Uterine fibroid therapy using interventional radiology mini-invasive treatments: current perspective. Med Oncol 2017; 34:52. [CrossRef]
30. Dong X, Yang Z. High-intensity focused ultrasound ablation of uterine localized adenomyosis. Curr Opin Obstet Gynecol 2010; 22:326330. [CrossRef]

31. Ismail SZ, Bilgen M. Use of depth dependent attenuation characteristics of thermal energy deposition to increase spatial uniformity of HIFU ablation in large uterine fibroids. Med Instrument 2013; 1:1. [CrossRef]

32. LeBlang SD, Hoctor K, Steinberg FL. Leiomyoma shrinkage after MRI-guided focused ultrasound treatment: report of 80 patients. AJR Am J Roentgenol 2010; 194:274-280. [CrossRef]

33. Duc NM, Keserci B. Review of influential clinical factors in reducing the risk of unsuccessful MRI-guided HIFU treatment outcome of uterine fibroids. Diagn Interv Radiol 2018; 24:283291. [CrossRef]

34. Keserci B, Duc NM. Magnetic resonance imaging parameters in predicting the treatment outcome of high-intensity focused ultrasound ablation of uterine fibroids with an immediate nonperfused volume ratio of at least $90 \%$. Acad Radiol 2018; 25:1257-1269. [CrossRef]

35. Keserci B, Duc NM. Magnetic resonance imaging features influencing high-intensity focused ultrasound ablation of adenomyosis with a nonperfused volume ratio of $\geq 90 \%$ as a measure of clinical treatment success: retrospective multivariate analysis. Int J Hyperthermia 2018; 11:1-11. [CrossRef]

36. Duc NM, Huy HQ, Keserci B. Adverse events of focused ultrasound surgery for uterine fibroids and adenomyosis. Rep Med Imaging 2018; 11:15-26. [CrossRef]

37. Liu Y, Zhang WW, He M, et al. Adverse effect analysis of high-intensity focused ultrasound in the treatment of benign uterine diseases. Int J Hyperthermia 2018; 35:56-61. [CrossRef]

38. Aoun $F$, Marcelis $Q$, Roumeguere T. Minimally invasive devices for treating lower urinary tract symptoms in benign prostate hyperplasia: technology update. Res Rep Urol 2015; 7:125136. [CrossRef]

39. Linares-Espinos E, Carneiro A, Martínez-Salamanca Jl, et al. New technologies and techniques for prostate cancer focal therapy: a review of the current literature. Minerva Urol Nefrol 2018; 70:252-263.

40. Blana A, Walter B, Rogenhofer S, Wieland WF. High-intensity focused ultrasound for the treatment of localized prostate cancer: 5 -year experience. Urology 2004; 63:297-300. [CrossRef]

41. Ripert T, Azémar MD, Ménard J, et al. Six years' experience with high-intensity focused ultrasonography for prostate cancer: oncological outcomes using the new 'Stuttgart' definition for biochemical failure. BJU Int 2011; 107:1899_ 1905. [CrossRef]

42. Crouzet $S$, Chapelon JY, Rouvière $\mathrm{O}$, et al. Whole-gland ablation of localized prostate cancer with high-intensity focused ultrasound: oncologic outcomes and morbidity in 1002 patients. Eur Urol 2014; 65:907-914. [CrossRef]

43. Mearini L, D'Urso L, Collura D, Nunzi E, Muto G, Porena M. High-intensity focused ultrasound for the treatment of prostate cancer: A prospective trial with long-term follow-up. Scand J Urol 2015; 49:267-274. [CrossRef]
44. Ahmed HU, Hindley RG, Dickinson L, et al. Focal therapy for localised unifocal and multifocal prostate cancer: a prospective development study. Lancet Oncol 2012; 13:622-632. [CrossRef]

45. Napoli A, Anzidei M, De Nunzio C, et al. Real-time magnetic resonance-guided high-intensity focused ultrasound focal therapy for localised prostate cancer: preliminary experience. Eur Urol 2013; 63:395-398. [CrossRef]

46. Chin JL, Billia M, Relle J, et al. Magnetic resonance imaging guided transurethral ultrasound ablation of prostate tissue in patients with localized prostate cancer: a prospective phase 1 clinical trial. Eur Urol 2016; 70:447-455. [CrossRef]

47. Xu WF, Zhang HB, Lin Z, et al. Transrectal high-intensity focused ultrasound for treatment of benign prostatic hyperplasia: report of 262 cases. Nan Fang Yi Ke Da Xue Bao 2010; 30:1906-1908. [CrossRef]

48. Lü J, Hu W, Wang W. Sonablate-500 transrectal high-intensity focused ultrasound (HIFU) for benign prostatic hyperplasia patients. J Huazhong Univ Sci Technolog Med Sci 2007; 27:671-674. [CrossRef]

49. Ljungberg B, Bensalah K, Canfield S, et al. EAU guidelines on renal cell carcinoma: 2014 update. Eur Urol 2015; 67:913-924. [CrossRef]

50. Illing RO, Kennedy JE, Wu F, et al. The safety and feasibility of extracorporeal high-intensity focused ultrasound (HIFU) for the treatment of liver and kidney tumours in a Western population. Br J Cancer 2005; 93:890-895. [CrossRef]

51. Ritchie RW, Leslie TA, Turner GD, et al. Laparoscopic high-intensity focused ultrasound for renal tumours: a proof of concept study. BJU Int 2011; 107:1290-1296. [CrossRef]

52. Cranston D. A review of high intensity focused ultrasound in relation to the treatment of renal tumours and other malignancies. Ultrason Sonochem 2015; 27:654-658. [CrossRef]

53. Kohrmann KU, Michel MS, Gaa J, Marlinghaus E, Alken P. High intensity focused ultrasound as noninvasive therapy for multilocal renal cell carcinoma: case study and review of the literature. J Urol 2002; 167:2397-2403. [CrossRef]

54. Ritchie R, Collin J, Coussios C, Leslie T. Attenuation and de-focusing during high-intensity focused ultrasound therapy through peri-nephric fat. Ultrasound Med Biol 2013; 39:1785-1793. [CrossRef]

55. Ritchie RW, Leslie T, Phillips R, et al. Extracorporeal high intensity focused ultrasound for renal tumours: a 3-year follow-up. BJU Int 2010; 106:1004-1009. [CrossRef]

56. Wu F, Wang ZB, Chen WZ, Bai J, Zhu H, Qiao TY. Preliminary experience using high intensity focused ultrasound for the treatment of patients with advanced stage renal malignancy. J Urol 2003; 170:2237-2240. [CrossRef]

57. Harding D, Giles SL, Brown MRD, et al. Evaluation of quality of life outcomes following palliative treatment of bone metastases with magnetic resonance-guided high intensity focused ultrasound: an international multicentre study. Clin Oncol 2018; 30:233-242. [CrossRef]

58. Chan M, Dennis $K$, Huang $Y$, et al. Magnetic resonance-guided high-intensity-focused ultrasound for palliation of painful skeletal metastases: a pilot study. Technol Cancer Res Treat 2017; 16:570-576. [CrossRef] 
59. Liberman B, Gianfelice D, Inbar Y, et al. Pain palliation in patients with bone metastases using MR-guided focused ultrasound surgery: a multicenter study. Ann Surg Oncol 2009; 16:140146. [CrossRef]

60. Napoli A, Anzidei M, Marincola BC, et al. Primary pain palliation and local tumor control in bone metastases treated with magnetic resonance-guided focused ultrasound. Invest Radiol 2013; 48:351-358. [CrossRef]

61. Hurwitz MD, Ghanouni P, Kanaev SV, et al. Magnetic resonance-guided focused ultrasound for patients with painful bone metastases: phase III trial results. J Natl Cancer Inst 2014; 23:106. [CrossRef]

62. Chen W, Zhu H, Zhang L, et al. Primary bone malignancy: effective treatment with high-intensity focused ultrasound ablation. Radiology 2010; 255:967-978. [CrossRef]

63. Yu W, Tang L, Lin F, et al. High-intensity focused ultrasound: noninvasive treatment for local unresectable recurrence of osteosarcoma. Surg Oncol 2015; 24:9-15. [CrossRef]

64. Atesok Kl, Alman BA, Schemitsch EH, et al. Osteoid osteoma and osteoblastoma. J Am Acad Orthop Surg 2011; b19:678-689. [CrossRef]

65. Napoli A, Bazzocchi A, Scipione R, et al. Noninvasive therapy for osteoid osteoma: a prospective developmental study with $\mathrm{mr}$ imaging-guided high-intensity focused ultrasound. Radiology 2017; 285:186-196. [CrossRef]

66. Sharma KV, Yarmolenko PS, Celik H, et al. Comparison of Noninvasive High-Intensity Focused Ultrasound with Radiofrequency Ablation of Osteoid Osteoma. J Pediatr 2017; 190:222-228. [CrossRef]

67. Bazzocchi A, Napoli A, Sacconi B, et al. MRI-guided focused ultrasound surgery in musculoskeletal diseases: the hot topics. Br J Radiol 2016; 89:20150358. [CrossRef]

68. Ghanouni P, Kishore S, Lungren MP, et al. treatment of low-flow vascular malformations of the extremities using MR-guided high intensity focused ultrasound: preliminary experience. JVasc Interv Radiol 2017; 28:1739-1744. [CrossRef]

69. Izumi M, Ikeuchi M, Kawasaki M, et al. MR-guided focused ultrasound for the novel and innovative management of osteoarthritic knee pain. BMC Musculoskelet Disord 2013; 14:267. [CrossRef]

70. Weeks EM, Platt MW, Gedroyc W. MRI-guided focused ultrasound (MRgFUS) to treat facet joint osteoarthritis low back pain--case series of an innovative new technique. Eur Radiol 2012; 22:2822-2835. [CrossRef]

71. Ghanouni P, Dobrotwir A, Bazzocchi A, et al. Magnetic resonance-guided focused ultrasound treatment of extra-abdominal desmoid tumors: a retrospective multicenter study. Eur Radiol 2017; 27:732-740. [CrossRef]
72. Visioli AG, Rivens IH, ter Haar GR, et al. Preliminary results of a phase I dose escalation clinical trial using focused ultrasound in the treatment of localised tumours. Eur J Ultrasound 1999; 9:11-18. [CrossRef]

73. de Senneville BD, Moonen C, Ries M. MRI-guided HIFU methods for the ablation of liver and renal cancers. Adv Exp Med Biol 2016; 880:4363. [CrossRef]

74. Ng KK, Poon RT, Chan SC, et al. High-intensity focused ultrasound for hepatocellular carcinoma: a single-center experience. Ann Surg 2011; 253:981-987. [CrossRef]

75. Chen L, Wang K, Chen Z. et al. High intensity focused ultrasound ablation for patients with inoperable liver cancer. Hepatogastroenterology 2015; 62:140-143.

76. Okada A, Murakami T, Mikami K, et al. A case of hepatocellular carcinoma treated by $\mathrm{mr}$ - guided focused ultrasound ablation with respiratory gating. Magn Res Med Sci 2006; 5:167-171. [CrossRef]

77. Wang K, Zhu H, Meng Z, et al. Safety evaluation of high-intensity focused ultrasound in patients with pancreatic cancer. Onkologie 2013 36:88-92. [CrossRef]

78. Sung HY, Jung SE, Cho SH, et al. Long-term outcome of high-intensity focused ultrasound in advanced pancreatic cancer. Pancreas 2011; 40:1080-1086. [CrossRef]

79. Gao HF, Wang K, Meng ZQ, et al. High intensity focused ultrasound treatment for patients with local advanced pancreatic cancer. Hepatogastroenterology 2013; 60:1906-1910.

80. Xiong $\mathrm{LL}$, Hwang $\mathrm{JH}$, Huang $\mathrm{XB}$, et al. Early clinical experience using high intensity focused ultrasound for palliation of inoperable pancreatic cancer. JOP 2009; 10:123-129.

81. Wu F, Wang ZB, Zhu H, et al. Feasibility of US-guided high-intensity focused ultrasound treatment in patients with advanced pancreatic cancer: initial experience. Radiology 2005; 236:1034-1040. [CrossRef]

82. Zaccagna F, Anzidei M, Sandolo F, et al. MRgFUS for liver and pancreas cancer treatments: the Umberto I hospital experience. Transl Cancer Res 2014; 3:430-441.

83. Merckel LG, Knuttel FM, Deckers R, et al. First clinical experience with a dedicated MRI-guided high-intensity focused ultrasound system for breast cancer ablation. Eur Radiol 2016; 26:4037-4046. [CrossRef]

84. Gianfelice D, Khiat A, Amara M, Belblidia A, Boulanger $Y$. MR imaging-guided focused US ablation of breast cancer: histopathologic assessment of effectiveness-initial experience. Radiology 2003; 227:849-855. [CrossRef]
85. Gianfelice D, Khiat A, Amara M, Belblidia A Boulanger Y. MR imaging-guided focused ultrasound surgery of breast cancer: correlation of dynamic contrast-enhanced MRI with histopathologic findings. Breast Cancer Res Treat 2003; 82:93-101. [CrossRef]

86. Wu F, Wang ZB, Cao YD, et al. A randomized clinical trial of high-intensity focused ultrasound ablation for the treatment of patients with localized breast cancer. Br J Cancer 2003; 89:2227-2233. [CrossRef]

87. Furusawa H, Namba K, Thomsen S, et al. Magnetic resonance-guided focused ultrasound surgery of breast cancer: reliability and effectiveness. J Am Coll Surg 2006; 203:54-63. [CrossRef]

88. Guan L, Xu G. Damage effect of high-intensity focused ultrasound on breast cancer tissues and their vascularities. World J Surg Oncol 2016; 26;14:153. [CrossRef]

89. Peek MCL, Ahmed M, Scudder J, et al. High-intensity focused ultrasound in the treatment of breast fibroadenomata (HIFU-F trial). Int J Hyperthermia 2018; 34:1002-1009. [CrossRef]

90. Kovatcheva R, Guglielmina JN, Abehsera M, et al. Ultrasound-guided high-intensity focused ultrasound treatment of breast fibroadenoma-a multicenter experience. J Ther Ultrasound 2015; 3:1. [CrossRef]

91. Gharib H, Papini E, Garber JR, et al. American Association of Clinical Endocrinologists, American College of Endocrinology, and Associazione Medici Endocrinologi Medical Guidelines for Clinical Practice for the diagnosis and management of thyroid nodules - 2016 Update. Endocr Pract 2016; 22:622-639. [CrossRef]

92. Haugen BR, Alexander EK, Bible KC, et al. 2015 American Thyroid Association Management Guidelines for Adult Patients with Thyroid Nodules and Differentiated Thyroid Cancer: The American Thyroid Association Guidelines Task Force on Thyroid Nodules and Differentiated Thyroid Cancer. Thyroid 2016; 26:1-133. [CrossRef]

93. Bergenfelz A, Jansson S, Kristoffersson A, et al. Complications to thyroid surgery: results as reported in a database from a multicenter audit comprising 3,660 patients. Langenbecks Arch Surg 2008; 393:667-673. [CrossRef]

94. Lang BH, Woo YC, Wong CKH. High-intensity focused ultrasound for treatment of symptomatic benign thyroid nodules: a prospective study. Radiology 2017; 284:897-906. [CrossRef]

95. Lang BHH, Woo YC, Chiu KW. Two-year efficacy of single-session high-intensity focused ultrasound (HIFU) ablation of benign thyroid nodules. Eur Radiol 2019; 29:93-101. [CrossRef]

96. Focused Ultrasound Foundation. https:// www.fusfoundation.org/diseases-and-conditions-all/overview. (Accessed 07 Jan 2019). 